\title{
Penyuluhan Seni Batik pada Kelompok PKK Padukuhan Karangwetan Tegaltirto, Berbah, Sleman, Yogyakarta
}

${ }^{1}$ Sugeng Wardoyo, ${ }^{2}$ Tri Wulandari

${ }_{1,2}$ Program Studi Kriya, Fakultas Seni Rupa Institut Seni Indonesia Yogyakarta Jalan Parangtritis Km 6,5, Sewon, Bantul, Daerah Istimewa Yogyakarta 55188 No. Tlp.: +6281393039442,E-mail:sgngwardoyo@gmail.com ${ }^{1}$ No. Tlp.: +6282220653303,E-mail: triwulandari.kriya@gmail.com² 


\title{
Penyuluhan Seni Batik pada Kelompok PKK Padukuhan Karangwetan Tegaltirto, Berbah, Sleman, Yogyakarta
}

\author{
${ }^{1}$ Sugeng Wardoyo, ${ }^{2}$ Tri Wulandari \\ ${ }^{1,2}$ Program Studi Kriya, Fakultas Seni Rupa \\ Institut Seni Indonesia Yogyakarta \\ Jalan Parangtritis Km 6,5, Sewon, Bantul, Daerah Istimewa Yogyakarta 55188 \\ No. Tlp.: +6281393039442, E-mail:sgngwardoyo@gmail.com ${ }^{1}$ \\ No. Tlp.: +6282220653303,E-mail: triwulandari.kriya@gmail.com²
}

\begin{abstract}
Abstrak
Anggota kelompok PKK Karangwetan, Tegaltirto, Berbah tergolong pemula atau awal dalam bidang kerajinan batik. Tentu mereka belum mempunyai pengetahuan yang cukup tentang proses batik. Masih kurangnya pengetahuan dan keterampilan dalam bidang desain dan teknik batik sampai perwujudan produk menjadi permasalahan utama. Adanya pelaksanaan program penyuluhan seni ini mencoba menawarkan alternatif program keterampilan tekstil khususnya teknik batik tulis dan teknik pewarnaan celup. Hal ini bertujuan untuk memberikan pengetahuan dan wawasan tentang cara membuat desain motif batik yang diwujudkan dari produk elemen interior hingga penguasaan ketereampilan khusus teknik dasar batik tulis dan teknik pewarnaan celup. Pelaksanaan kegiatan penyuluhan seni ini menggunakan metode ceramah dan metode praktik. Hasil penyuluhan seni batik berupa produk elemen interior, seperti taplak meja dan sarung bantal. Program penyuluhan seni ini dilaksanakan dengan konsep pelatihan keterampilan batik, telah menjadi bukti nyata bahwa seni batik masih dapat dikembangkan dan dilestarikan keberadaannya, serta diharapkan ada tindak lanjut dengan pelaksanaan program pendampingan lainnya yang saling bersinergi dan berkesinambungan.
\end{abstract}

Kata kunci: seni batik, produk interior, batik tulis, pewarnaan celup

\section{Batik Art Training to PKK Group in Karangwetan Hamlet Tegaltirto, Berbah, Sleman, Yogyakarta}

\begin{abstract}
The members of PKK group in Karangwetan, Tegaltirto, Berbah are still within the novice or beginner level in batik arts and craft. They did not have sufficient knowledge in batik processing. The main problem lies in the lack of skill in designing and batik technique to realize the product to its finished form. This art training program tries to offer alternative to skill teaching and knowledge building in how to create batik design patterns in the form of interior products to the mastery of basic techniques skill in batik tulis (manually hand-drawn motifs) and dip dyeing technique. In the implementation of art counseling activities this time using lecture methods and practice methods. This batik art extension produces interior element products such as tablecloths and pillowcases. This art counseling program is carried out with the concept of batik skills training, it has become a concrete proof that batik art can still be developed and preserved in its existence, and it is expected that there will be other mentoring program follow-ups that synergizes with previous program and forms a continuity.
\end{abstract}

Keywords: batik art, interior products, batik tulis, dip dye coloring 


\section{PENDAHULUAN}

Kota Yogyakarta telah dikenal sebagai pusat kebudayaan yang memiliki potensi berlimpah ruah nyaris tidak terbatas. Berbagai macam bentuk dan produk seni dan budaya dapat ditemui di daerah ini (Wardoyo et al., 2019). Daerah Istimewa Yogyakarta memiliki empat daerah kabupaten dan satu kota, masingmasing daerah mempunyai potensi yang istimewa. Kabupaten Bantul dengan pusat pemerintahan Bantul, Sleman dengan Sleman, Kulon Progo dengan Wates, dan Gunung Kidul dengan Wonosari. Beberapa potensi yang ada di daerah Kabupaten Sleman, potensi batik yang menjadi ciri khas motif antara lain tanaman salak, sinom parijotho, dan pesona wisata alam yang menjadi andalan.

Selain beberapa potensi yang disebutkan tersebut mengenai potensi daerah Kabupaten Sleman, dalam kegiatan penyuluhan seni ini akan lebih fokus lagi di daerah Tegaltirto. Desa Tegaltirto terletak di Kecamatan Berbah. Desa ini merupakan penggabungan tiga kelurahan lama, yaitu Krikilan, Candirejo, dan Tegalsari. Kelurahan lama tersebut membawahi beberapa wilayah pedukuhan antara lain Kelurahan Krikilan terdiri dari Pedukuhan Jagalan, Tlogowono, Blendangan, Berbah, Krikilan. Kelurahan Candirejo membawahi Pedukuhan Kuncen, Sompilan, Karangwetan, Candirejo dan Semoya. Kelurahan Tegalsari membawahi Pedukuhan Kadisono, Kuton, Tegalsari, dan Pendem.

Penduduk Tegaltirto mayoritas bermata pencaharian pada bidang pertanian. Hal ini sesuai dengan kondisi geografis yang didominasi lahan pertanian dan ekonomi masih bersifat agraris. Program penyuluhan seni ini mencoba menawarkan alternatif program keterampilan tekstil khususnya teknik batik tulis dan teknik pewarnaan celup. Kelompok PKK di Padukan Karangwetan sebagai objek program penyuluhan, melalui program ini diharapkan anggota PKK Karangwetan mampu membuat desain motif batik yang diwujudkan dalam produk elemen interior sampai pada tahap pewarnaan dan finishing.

Anggota kelompok PKK Karangwetan Tegaltirto Berbah tergolong pemula atau awal dalam bidang kerajinan batik, tentunya belum mempunyai pengetahuan yang cukup tentang proses batik. Masih kurangnya pengetahuan dan keterampilan dalam bidang desain dan teknik batik sampai perwujudan produk menjadi permasalahan utama. Di satu sisi mereka mempunyai harapan agar kegiatan penyuluhan seni ini bisa menjadi usaha sampingan, bahkan menjadi usaha pokok atau sampingan yang bisa meningkatkan taraf ekonomi mereka. Pelatihan-pelatihan tentang keterampilan batik yang diselenggarakan oleh pemerintah dan swasta tidak sering diadakan, dan walaupun ada pesertanya terbatas. Kesempatan untuk mengikuti kegiatan pelatihan-pelatihan menjadi belum maksimal, padahal mereka sangat membutuhkan tambahan pengetahuan dan keterampilan seni batik demi mewujudkan harapan mereka.

Berdasarkan permasalahan inilah, program penyuluhan seni ini dipandang perlu untuk ditindaklanjuti. Diharapkan dari program ini dapat menambah pengetahuan keterampilan membatik khususnya penerapan teknik mewarna kimia naptol, serta diharapkan muncul motif batik khas Tegaltirto yang mempunyai nilai estetik dan makna filosofi. Dengan tingkat keterampilan yang 
memadai, diharapkan kualitas produk batik dari desa Tegaltirto ini dapat bersaing dan diterima pasar secara luas.

Tujuan diadakannya penyuluhan seni ini adalah: (1) meningkatkan wawasan, pengetahuan, kemampuan, dan keterampilan baik secara pengetahuan berupa pemahaman teknis dan pragmatis dalam bidang desain maupun keterampilan membatik dengan bahan warna kimia bagi para peserta dan (2) mendorong para anggota agar memiliki kemampuan dan motivasi dalam rangka pengembangan bidang keterampilan dan kewirausahaan.

Teori mengenai teknik batik, Susanto (1980) telah menjelaskan bahwa teknik membuat batik merupakan proses-proses pengerjaan dari persiapan mori batik sampai menjadi kain batik. Di dalam proses persiapan meliputi nggirah atau ngetel nganji, dan ngemplong, sedangkan dalam proses membuat batik mencakup pekerjaan utama, seperti pelekatan lilin, pewarnaan batik, dan menghilangkan lilin

Teknik resist dye pada dasarnya banyak dikenal di berbagai negara. Teknik perintangan warna menggunakan bahan perintang warna seperti bubur dari gandum, beras ketan, dan parafin, serta menggunakan alat bantu kuas sebagai alat melukis. Berbeda dengan yang teknik resist dye di Indonesia yang menggunakan canting sebagai alat melukis dan lilin malam sebagai bahan perintang warna sehingga disebut dengan membatik (Djoemena, 1986). Dalam penyuluhan seni batik ini menggunakan teknik batik tulis dengan alat bantu canting tulis.

Proses pewarnaan dalam batik dibagi dalam dua kategori, yaitu teknik pewarnaan colet dan teknik pewarnaan celup. Proses mewarna dengan teknik celup dikenal dalam dunia batik dengan teknik kerek. Teknik ini membutuhkan dua orang dalam proses pengerjaannya yang saling berhadapan dengan saling menarik dan mengulurkan kain pada saat proses pewarnaan kain batik (Sidiq, 2016).

Sejak diperkenalkannya zat warna sintetis oleh Belanda di Indonesia, para pengguna zat warna alam beralih menggunakan zat warna sintetis atau kimia. Hal yang terpenting dengan menggunakan zat warna sintetis memiliki kelebihan, seperti mudah penggunaannya, cepat proses pewarnaannya, dan murah harganya sehingga dapat memberikan keuntungan (Sedjati et al., 2021).

Penyuluhan seni batik ini memiliki batasan teknik yang diajarkan pada aspek penguasaan teknik pewarnaan batik dasar, yakni teknik celup. Zat warna sintetis yang digunakan adalah warna naptol. Hal ini bertujuan untuk membekali anggota kelompok PKK Karangwetan agar memiliki keterampilan khusus teknik dasar batik tulis yang diimbangi dengan teknik perwanaan celup.

\section{METODE PENGABDIAN}

Pada kegiatan penyuluhan di Kelompok PKK Karangwetan, penulis menggunakan beberapa metode pengajaran/pembelajaran praktis. Metode tersebut digunakan dengan mempertimbangkan kondisi ruang lingkup dan kemampuan anggota kelompok atau peserta. Pelaksanaan kegiatan penyuluhan seni ini menggunakan metode ceramah dan metode praktik. Hal ini disesuaikan atau bersifat fleksibel menyesuaikan situasi dan kondisi. Guna membangkitkan semangat para peserta dalam mengikuti pelatihan, penyuluh selalu memompa motivasi para peserta pelatihan agar target penguasaan teknik batik tulis dasar dapat terwujud.

Metode ceramah sering disebut dengan metode konvensional atau 
tradisonal. Hingga saat ini metode ceramah ini masih digunakan dalam pelaksanaan pembelajaran sebagai alat komunikasi antara pemberi materi dan peserta didik dalam membahasa suatu materi (Lutfi et al., 2020).

Dalam penggunaan metode ceramah terdapat serangkaian metode yang saling terkait dari metode ceramah, tanya jawab, dan diskusi, sedangkan metode praktik mencakup demonstrasi dan eksperimen. Metode ceramah digunakan untuk penyampaian materi yang dilakukan oleh pelatih/pemateri dengan cara menuturkan secara lisan atau penjelasan secara langsung kepada anggota kelompok PKK Karangwetan. Tanya jawab dilakukan dengan cara menanyakan hal-hal yang belum dipahami atau dimengerti terkait materi atau praktik selama kegiatan penyuluhan berlangsung. Diskusi dilakukan untuk menentukan materi yang akan dipelajari, teknis pelaksanaan, jadwal latihan, dan lain-lain.

Metode praktik seperti metode demonstrasi digunakan untuk memperlihatkan suatu proses, mekanisme, atau cara kerja suatu alat yang berkaitan dengan bahan yang digunakan oleh peserta didik (Lutfi et al., 2020). Dalam penyuluhan seni batik ini terkait dengan tata cara membuat desain, memindahkan pola batik, melekatkan lilin, mewarna, merebus kain, hingga finishing produk. Metode eksperimen merupakan metode yang memberikan kesempatan kepada peserta penyuluhan baik secara perorangan maupun kelompok untuk melaksanakan suatu praktik aru percobaan di lapangan yang bertujuan untuk menemenukan pengetahuna dan pengalaman baru (Lutfi et al., 2020). Dalam penyuluhan seni batik ini, ekperimen berguna untuk mengasah kemampuan praktis dan keterampilan praktik dalam proses membatik dari awal proses persiapan hingga proses akhir.

\section{HASIL DAN PEMBAHASAN}

Karya kriya merupakan representasi karya budaya masyarakat luas yang melekat dengan aktivitas kehidupan sehari-hari, seperti elemen interior rumah, alat dapur, furnitur serta benda-benda yang ada dan dekat dengan aktivitas manusia juga termasuk dalam karya kriya (Lufiani, 2018). Fenomena menggali potensi budaya lokal dan potensi karya kriya lokal yang ada di wilayah Padukuhan Karangwetan merupakan upaya untuk mengeksplorasi potensi lokal yang ada saat ini. Penggarapan budaya lokal yang dimanifestasi menjadi produk unggulan daerah diharapkan mampu menjadi solusi melalui penguatan pelatihan seni.

Dari beberapa permasalahan seperti yang telah dipaparkan sebelumnya, tim penyuluh memberikan penguatan pelatihan seni yang terkait dengan pelatihan desain, teknik membatik, serta pewarnaan bagi anggota PKK Karangwetan. Program pelatihan yang akan dilaksanakan ini bertitik tolak dari pengetahuan dan keterampilan yang telah dimiliki oleh para anggota kelompok, yaitu meningkatkan pengetahuan dan keterampilan di bidang desain dan teknik pewarnaan dasar batik, serta meningkatkan kreativitas para anggota kelompok dalam berkarya membuat produk batik.

Adapun materi yang diberikan dalam pelatihan baik bersifat teoretis maupun praktik mencakup:

1. wawasan dan pengetahuan tentang seni batik, yang meliputi pengertian tentang teknik batik, pengetahuan tentang alat dan bahan batik, pengetahuan tentang proses pewarnaan dan teknik batik tutup celup; 
2. wawasan dan pengetahuan tentang desain produk batik meliputi pengenalan berbagai macam produk batik dan pengetahuan tentang cara membuat desain motif batik;

3. praktik membuat desain motif batik meliputi praktik membuat desain motif batik berdasarkan kekhasan lokal, praktik membuat motif batik yang baru dengan sumber ide dari alam sekitar, praktik membatik tulis, dan praktik mewarna teknik celup.

Khalayak sasaran penyuluhan ini adalah anggota kelompok PKK Karangwetan, Tegaltirto, Berbah, Sleman, Yogyakarta, beranggotakan 10 ibu PKK Karangwetan yang mempunyai semangat tinggi dalam mengikuti kegiatan penyuluhan seni. Adapun tempat kegiatan penyuluhan akan dilaksanakan di rumah Dukuh Karangwetan, Bapak Nanang, Amd.
Tempat ini dipilih dengan pertimbangan tempat yang luas dan strategis serta memiliki saran prasarana yang memadahi. Waktu kegiatan penyuluhan dilaksanakan dalam kurun waktu mulai 19 Maret sampai dengan 4 Mei 2019, selama 12 kali pertemuan yang secara detail dilaksanakan dalam 2 kali pertemuan dalam seminggu. Jadwal pertemuan akan ditentukan berdasarkan kesepakatan antara penyuluh dan peserta.

Serangkaian kegiatan praktik membatik, mewarna, nemboki, mewarna kedua, merebus kain, hingga finishing produk batik diikuti oleh peserta PKK Karangwetan dengan antusias dan aktif bereksperimen. Hal ini dapat ditunjukkan dengan jelas pada gambar 1, gambar 2, gambar 3, gambar 4, gambar 5, gambar 6, dan gambar 7 .

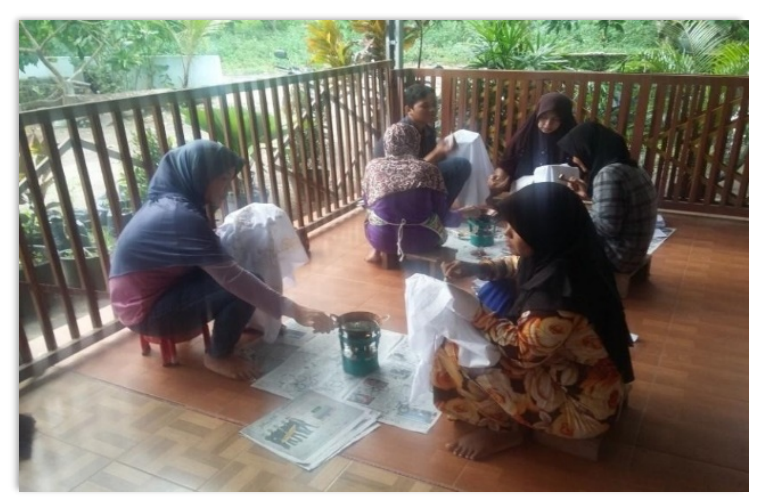

Gambar 1 Proses Membatik

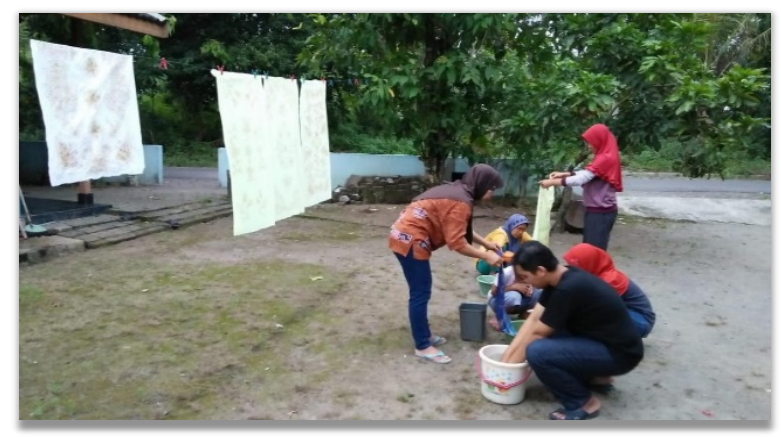

Gambar 2 Proses Mewarna Pertama 


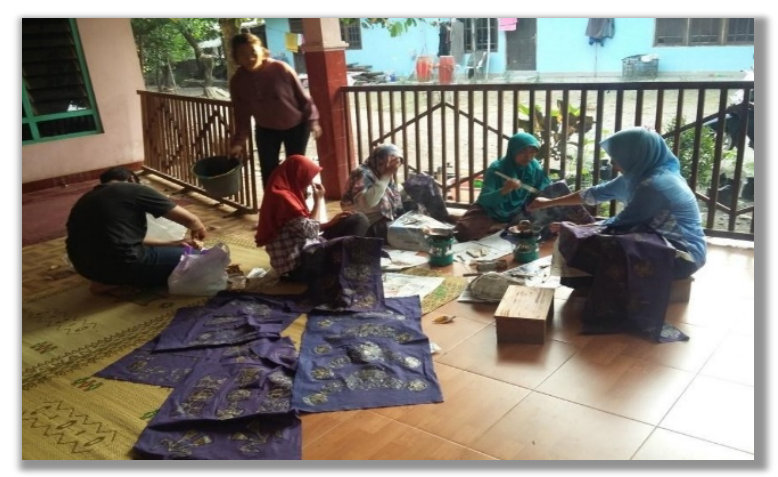

Gambar 3 Proses Nemboki

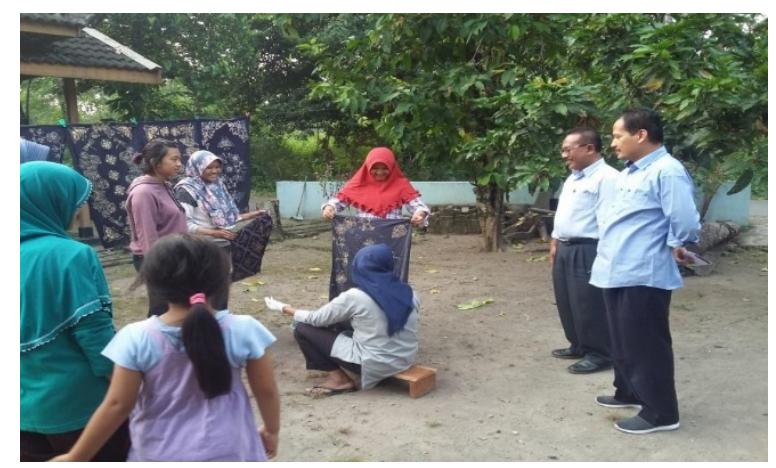

Gambar 4 Proses Mewarna Kedua

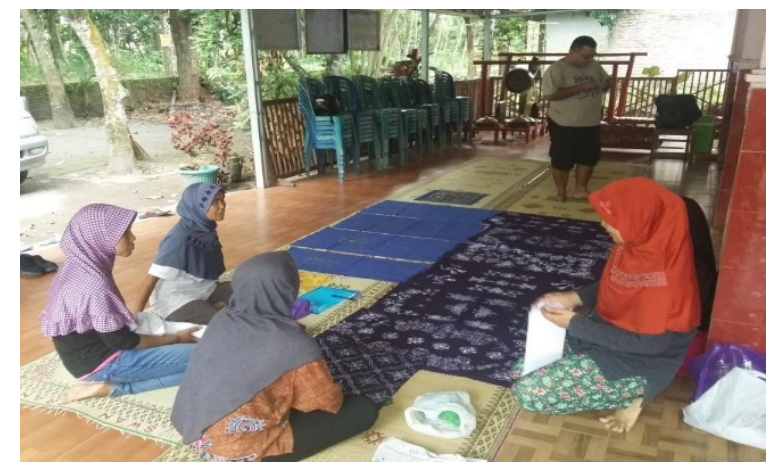

Gambar 5 Proses Merebus Kain 


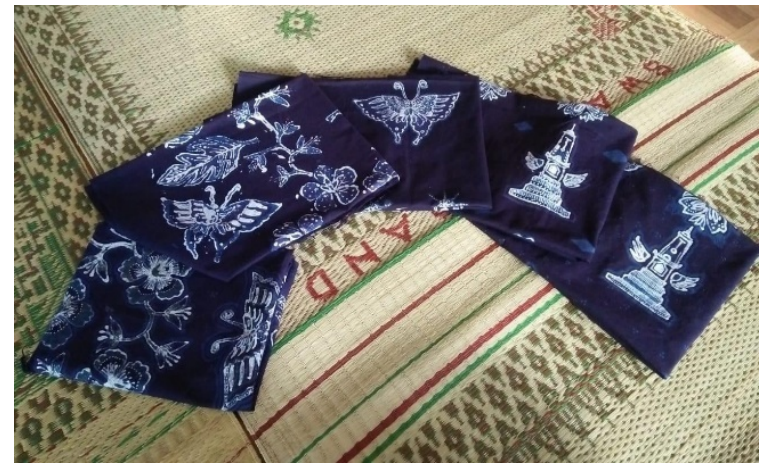

Gambar 6 Hasil Sarung Bantal Batik

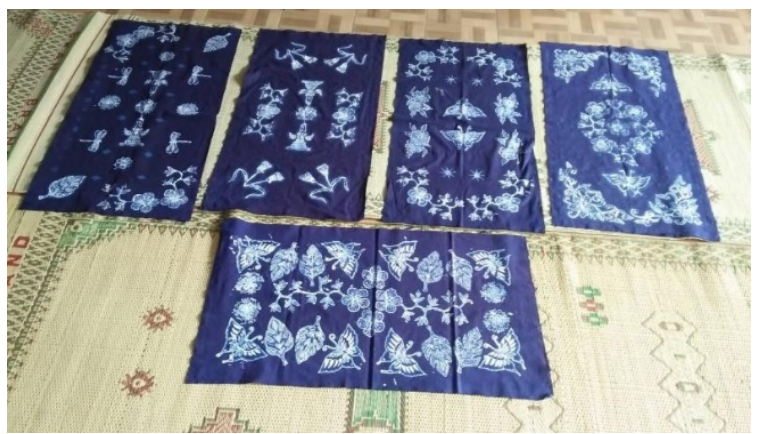

Gambar 7 Hasil Taplak Batik

Dalam pelaksanaan program penyuluhan ini tidak banyak menemui kendala yang berarti dikarenakan kekompakan dan semangat kelompok ibuibu PKK Padukuhan Karangwetan ini sangat membanggakan. Yang menjadi cacatan hanya pada kelengkapan sarana dan prasarana, terutama pada sarana pewarnaan masih perlu mendapat dukungan dan perhatian untuk lebih memaksimalkan hasil pewarnaan.

Hasil yang dicapai dalam program penyuluhan ini adalah adanya (1) peningkatan pemahaman dan penguasaan semua materi yang diberikan dalam pembinaan; (2) peningkatan pengetahuan, keterampilan, dan kreativitas peserta dalam membuat desain produk dan desain motif batik; (3) peningkatan pengetahuan dan keterampilan peserta dalam bidang batik tulis, khususnya proses pelilinan batik tulis dan teknik pewarnaan celup; (4) peningkatan keterampilan membuat desain batik dan mewujudkannya menjadi produk elemen interior; dan (5) pegembangan produk yang dihasilkan adalah berupa sarung bantal dan taplak meja dengan teknik tutup celup menggunakan pewarnaan naptol.

\section{SIMPULAN}

Seni kerajinan batik merupakan salah satu aset bangsa Indonesia yang perlu dilestarikan keberadaannya. Program Penyuluhan Seni tahun 2019 merupakan kelanjutan dari program-program sebelumnya. Penyuluhan seni kali ini pada kelompok ibu-ibu PKK Dusun Karangwetan, Tegaltirto, Berbah, Sleman, Yogyakarta; merupakan salah satu program rutin dari Lembaga Pengabdian Masyarakat Institut Seni Indonesia Yogyakarta dalam rangka melaksanakan Tridarma Perguruan 
Tinggi. Sesuai dengan visi dan misi dari program kegiatan ini adalah membantu masyarakat dalam rangka membina dan mengembangkan aset seni dan budaya dengan menjalin sinergi dengan masyarakat atau pemerintah daerah setempat.

\section{SARAN}

Program ini dilaksanakan dengan konsep pelatihan keterampilan batik telah menjadi bukti nyata bahwa seni batik masih dapat dikembangkan dan dilestarikan keberadaannya, serta diharapkan ada tindak lanjut dengan pelaksanaan program pendampingan lainnya yang saling bersinergi dan berkesinambungan.

\section{UCAPAN TERIMA KASIH}

Ucapan terima kasih disampaikan kepada LPPM ISI Yogyakarta atas dilaksanakannya Program Pengabdian Masyarakat Penyuluhan Seni Tahun 2019 dengan dana DIPA ISI Yogyakarta Tahun Anggaran 2019 sehingga pelaksanaan kegiatan penyuluhan seni ini dapat berjalan dengan lancar dan tepat waktu. Terima kasih kepada Lurah Tegaltirto dan kelompok PKK Padukuhan Karangwetan atas kerja samanya sehingga kegiatan penyuluhan seni ini dapat diselesaikan dengan baik dan lancar.

\section{DAFTAR PUSTAKA}

Djoemena, N. S. (1986). Ungkapan Sehelai Batik: Its Mystery and Meaning. Djambatan.

Lufiani, A. (2018). Transformasi Kriya Dalam Berbagai Konteks Budaya Pada Era Industri Kreatif. $A R S, 21(2)$.

Lutfi, Ardi, Yogica, R., Muttaqiin, A., \& Fitri, R. (2020). Metodologi Pembelajaran: Strategi, Pendekatan, Model, Metode Pembelajaran (Pertana). IRDHI.
Sedjati, D. P., Azkia, Z., \& Yantari, P. (2021). Eksperimentasi Kluwih (Artocarpus Camansi ) Sebagai Warna Alam Pada Tekstil. ARS, 24(1)

Sidiq, M. (2016). Panduan Teknik Batik Tulis: A Technical Guide To Make Handwritten Batik (Cetakan Pe). Permata Kreasi Media.

Susanto, S. (1980). Seni Kerajinan Batik Indonesia. Balai Penelitian Batik dan Kerajinan, Lembaga Penelitian Pendidikan Industri, Departeman Perindustrian RI.

Wardoyo, S., Hariyanto, I., \& Irawani, T. (2019). Penciptaan Produk Batik Eco Friendly Dengan Tema Kendaraan Tradisional Khas Yogyakarta Pit Onthel (Sepeda Kayuh) Sebagai Upaya Penguatan Industri Kreatif Kerakyatan Dan Pariwisata. Corak: Jurnal Seni Kriya, 8(1).https: / / doi.org/10.24821/corak. v8i1.2776 
